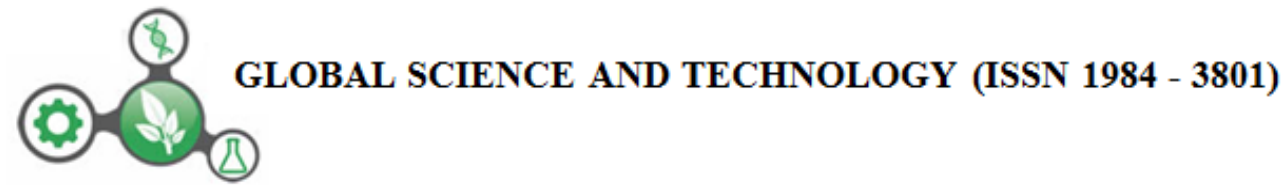

\section{HÍBRIDO SIMPLES DE MILHO (BRS 1030) SUBMETIDO A DIFERENTES SISTEMAS DE CULTIVO}

\author{
Arystides Resende Silva ${ }^{1 *}$, Agust Sales ${ }^{1}$, Carlos Alberto Costa Veloso ${ }^{1}$, Eduardo Jorge \\ Maklouf Carvalho ${ }^{1}$
}

\begin{abstract}
RESUMO: O consórcio de culturas, além de melhorar a qualidade do solo, proporciona maior produção por área do que o monocultivo. O estudo objetivou avaliar o desempenho do híbrido simples de milho BRS 1030 semeado em sistema iLPF, Santa Fé e Convencional. O delineamento experimental para análise das características agronômicas e produtivas do milho foi o de blocos casualizados, com seis repetições. Os valores de altura (planta e espiga) foram similares, comparando as médias dos sistemas. Os números de produtividade de grãos por ha não apresentaram diferença significativa, entretanto, verificou-se que os sistemas iLPF e Santa Fé, ambos com população cerca de $14 \%$ menor do que o sistema Convencional, proporcionaram maior produção por indivíduo, cerca de $13 \%$ superior à obtida no sistema Convencional. A produção de palhada foi superior no sistema Santa Fé $\left(5.612,68 \mathrm{~kg} \cdot \mathrm{ha}^{-1}\right)$ em relação aos demais sistemas. O desenvolvimento do milho nos sistemas iLPF e Santa Fé foram semelhantes e superiores ao sistema Convencional.
\end{abstract}

Palavras-chave: sistemas integrados, produção de grãos, características agronômicas.

\section{SIMPLE HYBRID OF MAIZE (BRS 1030) SUBJECTED THE DIFFERENT CULTIVATION OF SYSTEMS}

\begin{abstract}
The consortium of cultures, in addition to improve soil quality, provides greater production per area than the monoculture. The study aimed to evaluate the performance of simple corn hybrid BRS 1030 sown in iLPF system, Santa Fe and Conventional. The experimental lineation for the analysis the agronomic and productive characteristics of corn was a randomized block randomized, with six replications. The height values (plant and tenon) were similar comparing the means of the systems. The numbers of grain production per ha not present significant difference, in the meantime, it was found that the iLPF and Santa Fe systems, both with population about 14\% less than the conventional system, provided greater production per individual, about $13 \%$ higher than in the conventional system. The production of straw was higher in Santa Fe system (5612.68 kg.há ${ }^{-1}$ ) compared to the other systems. The development of the maize in iLPF and Santa Fe systems were similar and higher to the conventional system.
\end{abstract}

Key-words: integrated systems, grain production, agronomic characteristics.

\footnotetext{
1 Pesquisador da Embrapa Amazônia Oriental. *E-mail: arystides.silva@embrapa.br. Autor para correspondência.
}

Recebido em: 27/05/2014. Aprovado em: 30/11/2015.

\section{INTRODUÇÃO}

O milho é uma das culturas mais cultivadas no mundo. O Brasil é o terceiro maior produtor mundial com $7,5 \%$ de participação, ficando atrás apenas da China e Estados Unidos (EMBRAPA, 2013). A produção do milho se destaca no Brasil como 
o segundo cereal mais cultivado, com 15,5 milhões de hectares semeados na safra 2014/2015 e produção estimada de 83,5 milhões de toneladas (CONAB, 2015). Este cereal apresenta grande importância na formação da renda agrícola, pois, é matériaprima na indústria e devido à sua composição nutricional contribui na alimentação humana e animal, entrando como componente básico (SANTOS, 2010).

Uma cultivar de milho pode ser compreendida como todo material fornecido na forma de sementes para cultivo, normalmente. As sementes são divididas em dois grandes grupos: os híbridos $\mathrm{e}$ as variedades. Além das características genéticas de cada uma, a diferença básica entre esses dois materiais consiste na obtenção das sementes. Os híbridos são cultivares resultantes do acasalamento ou cruzamento entre dois genitores geneticamente diferentes. Dentre os híbridos, os mais comuns são os Simples, Duplos e Triplos. Geneticamente, o potencial produtivo dos híbridos é maior que o das variedades e entre os híbridos de linhagem, teoricamente, os híbridos simples são os mais produtivos e uniformes, e os híbridos duplos, os menos produtivos e menos uniformes (SILVA et al., 2014).

O híbrido simples de milho BRS 1030 destaca-se pela alta produtividade em relação aos outros híbridos do mercado associada à alta sanidade foliar. Além de ter excelente estabilidade produtiva e resistência ao acamamento e quebramento do colmo, sendo que, pode ser cultivado tanto em áreas acima e abaixo de $700 \mathrm{~m}$ de altitude. Este híbrido possui porte baixo e características que despertam o interesse do produtor e do mercado, como, tipo de grão semiduro e coloração de grãos laranja (PARENTONI et al., 2004).

O consórcio de milho com forragem reflete positivamente nas propriedades do solo aumentando a reciclagem de nutrientes e os teores de matéria orgânica e nutrientes deste, devido à grande produção de matéria orgânica e ao alto volume de raízes, (CRUSCIOL; $\quad$ BORGHI, 2007;
CALONEGO; POLETO; DOMINGUES, 2011). Desta forma, o consórcio destas espécies permite assim o uso racional da terra, além de proporcionar maior produção por área ao produtor, em relação ao monocultivo (BRINTHA; SERAN, 2009; GUEDES et al., 2010; SOUZA et al., 2011).

O sistema Santa Fé conceitua-se no cultivo de grãos, especialmente, o milho, em consórcio com forragem, principalmente, as do gênero Urochloa. As culturas anuais, devido ao elevado desenvolvimento inicial, manejadas de maneira adequada exercem alta competição sobre as forrageiras, e desse modo, não sofrem redução da capacidade produtiva de grãos, devido à energia sinergética criada entre pastagem e lavoura, favorece o aumento da produção de grãos, fibras, carne, leite e de agroenergia a custos reduzidos.

O sistema Santa Fé é realizado, anualmente, pode ser feito o plantio simultaneamente ao da cultura anual ou entre 10 a 20 dias após a emergência da mesma. Outra grande vantagem, o cronograma de atividades do produtor não sofre alteração e não necessita de maquinário especializado para a implantação. O solo é explorado de forma sustentável e viável, economicamente, quando relacionado aos modelos mais especializados (SOUZA et al., 2008; NASCIMENTO; CARVALHO, 2011).

O sistema de integração LavouraPecuária-Floresta (iLPF) permite a recuperação de áreas em estado de degradação através do cultivo consorciado em sucessão de rotação, potencializando os efeitos sinergéticos entre as espécies vegetais e a criação de animais, de forma racional, visando à sustentabilidade e uma maior produção por área (BALBINO et al., 2011). Através do uso mais eficiente dos recursos naturais, este sistema proporciona o aumento da produção de alimento e madeira reduzindo os riscos de produção devido às alternativas de renda do produtor (MARTHA JUNIOR; ALVES; CONTINI, 2011).

Diante dessas considerações, o objetivo deste trabalho foi avaliar o desempenho do híbrido simples de milho 
BRS 1030 semeado em sistema de integração Lavoura-Pecuária-Floresta (iLPF), sistema Santa Fé e sistema Convencional.

\section{MATERIAL E MÉTODOS}

$\mathrm{O}$ experimento foi conduzido na Fazenda Vitória localizado no município de Paragominas, situado na região nordeste do estado do Pará a uma altitude de 89 metros, situado $02^{\circ} 57^{\prime} 29,47^{\prime \prime} \mathrm{S}$ de latitude e $47^{\circ} 23^{\prime} 10,37^{\prime}$ 'W de longitude. O solo foi classificado como Latossolo amarelo textura argilosa (EMBRAPA, 2006), sendo as propriedades químicas e granulométricas avaliadas antes da instalação do experimento nas camadas 0-10 e 10-20 cm do solo utilizando a metodologia proposta pela EMBRAPA (1997), exceto a matéria orgânica (MO), que foi determinada pelo método de Walkley \& Black, descrito em Black (1965) (Tabela 1).

Tabela 1. Propriedades ${ }^{1}$ químicas e granulométricas da área experimental nas profundidades 0-10 e 10-20 cm (Paragominas - PA, 2009)

\begin{tabular}{|c|c|c|c|c|c|c|c|c|c|c|c|}
\hline $\begin{array}{l}\text { Prof. } \\
\text { (cm) }\end{array}$ & $\begin{array}{c}\mathbf{p H} \\
\left(\mathbf{H}_{2} \mathbf{O}\right)\end{array}$ & M.O. & $\underset{\left(\text { Mehlich }^{-1}\right)}{\mathbf{P}}$ & $\mathbf{C a}$ & Mg & $\mathbf{K}$ & Al & $\mathbf{H}+\mathbf{A l}$ & Areia & $\mathbf{S}$ & $\mathbf{A}$ \\
\hline & & dag. $\mathrm{kg}^{-1}$ & $\mathrm{mg} \cdot \mathrm{kg}^{-1}$ & \multicolumn{5}{|c|}{$\mathrm{cmol}_{\mathrm{c}} \cdot \mathrm{dm}^{-3}$} & \multicolumn{3}{|c|}{ g. $\mathrm{kg}^{-1}$} \\
\hline $0-10$ & 5,60 & 3,39 & 2,75 & 3,33 & 1,05 & 0,25 & 0,18 & 4,50 & 56 & 284 & 660 \\
\hline $10-20$ & 5,43 & 2,21 & 2,00 & 1,93 & 0,85 & 0,13 & 0,25 & 3,63 & 43 & 232 & 725 \\
\hline
\end{tabular}

${ }^{1}$ Análises realizadas no laboratório de Solos da Embrapa Amazônia Oriental. M.O. = Matéria Orgânica; P = Fósforo; $\mathrm{Ca}=$ Cálcio; $\mathrm{Mg}=$ Magnésio; $\mathrm{K}=$ Potássio; $\mathrm{Al}=$ Alumínio; $\mathrm{H}+\mathrm{Al}$ = Hidrogênio + Alumínio; $\mathrm{S}=\mathrm{Silte}$; $\mathrm{A}=$ Argila.

O clima da região é do tipo Aw, pela classificação de Koppen. A temperatura média anual varia entre $23,3^{\circ} \mathrm{C}$ a $27,3^{\circ} \mathrm{C}$ e a umidade relativa do ar apresenta média anual de $81 \%$. A precipitação média anual é de
$1.743 \mathrm{~mm}$. Os dados referentes à precipitação, umidade relativa e temperatura média durante a condução do experimento, estão apresentados na Tabela 2.

Tabela 2. Umidade relativa (UR), precipitação e temperatura média durante a condução do experimento (Paragominas - PA, 2009)

\begin{tabular}{ccccccc}
\hline Dados & Fevereiro & Março & Abril & Maio & Junho & Julho \\
\hline Precipitação $(\mathrm{mm})$ & 433 & 313 & 278 & 153 & 67 & 55 \\
Temperatura média $\left({ }^{\circ} \mathrm{C}\right)$ & 25,3 & 25,6 & 25,5 & 25,4 & 25,8 & 25,9 \\
UR $(\%)$ & 87,0 & 89,0 & 88,0 & 90,5 & 83,0 & 80,5 \\
\hline
\end{tabular}

Fonte: Inmet (2015).

O delineamento experimental utilizado foi o de blocos casualizados, com seis repetições. Os tratamentos constituíramse de três sistemas de cultivo de milho, sendo em sistema iLPF (consórcio com Urochloa ruziziensis e intercalado com mogno africano) em área de 4,05 ha, sistema Santa Fé (5 ha) e sistema Convencional (3 ha).

O milho (BRS 1030) foi semeado, em todos os sistemas, no mês de fevereiro de 2009 com espaçamento de 0,6 m, após aplicação de glifosato, com adubação de base de $330 \mathrm{~kg} \cdot \mathrm{ha}^{-1}$ da formulação 10-28-20. Em março e maio, foram realizadas adubações de cobertura com 200 kg.ha- ${ }^{-1}$ (Ureia $+\mathrm{KCl}, 2: 1$ ) e $180 \mathrm{~kg}$ (Ureia $+\mathrm{KCl}, 2: 1$ ), respectivamente. A colheita do milho foi realizada mecanicamente em julho de 2009.

Em março de 2009, foi realizado o plantio do mogno africano (Khaya ivorensis) no sistema iLPF em duas linhas no espaçamento $5 \times 5 \mathrm{~m}$, sendo $20 \mathrm{~m}$ a distância entre renques de árvores para o cultivo das culturas anuais e forragem, o que totalizou $28 \%$ de área por hectare ocupada pelas faixas dos renques e densidade de 160 árvores.ha ${ }^{-1}$. Foi aplicado $300 \mathrm{~g}$ de fosfato Arad e $100 \mathrm{~g}$ de super fosfato simples por cova. A adubação 
de cobertura foi realizada em maio de 2009, após o coroamento das mudas, com $60 \mathrm{~g}$ de ureia e $40 \mathrm{~g}$ de $\mathrm{KCl}$ por planta. Nos sistemas iLPF e Santa Fé, foi semeada, em maio de 2009, a forragem (Urochloa ruziziensis) (20 kg.ha ${ }^{-1}$ ) em consórcio com o milho.

A avaliação do milho foi realizada através da coleta de amostras em duas linhas de 5 metros lineares por faixa (área útil da parcela $7 \mathrm{~m}^{2}$ ), onde foram determinados: a produtividade de grãos da cultura em kg.ha ${ }^{-1}$; teor de umidade dos grãos (\%); estande de plantas (número de plantas/ha); altura das plantas (m) e altura da espiga do milho (m).

A produção de palhada (massa seca da parte aérea após a colheita) foi determinada em parcelas de $3,5 \mathrm{~m}^{2}$. $\mathrm{Na}$ avaliação da produção de forragem coletou-se amostras de $0,25 \mathrm{~m}^{2}$ em 7 repetições para determinar o peso de massa verde e seca (estufa a $65{ }^{\circ} \mathrm{C}$, com ventilação, por um período de 48 horas).

As análises estatísticas foram realizadas, utilizando-se o programa estatístico SISVAR $^{\circledR}$. As médias foram agrupadas pelo teste de Scott-Knott a 5\% de probabilidade.

\section{RESULTADOS E DISCUSSÃO}

Os valores de altura (planta e espiga) não apresentaram diferença entre os sistemas estudados, a altura média de plantas foi de $2,19 \mathrm{~m}$, com valor mínimo de $2,18 \mathrm{~m}$ para os sistemas iLPF e Santa Fé e valor máximo de 2,20 m para o sistema Convencional, a altura de espigas apresentou média de $1,18 \mathrm{~m}$, com valor mínimo de 1,16 para o iLPF e valor máximo de $1,21 \mathrm{~m}$ para $\mathrm{o}$ sistema Convencional (Tabela 3).

Tabela 3. Características agronômicas e de produção do milho BRS 1030 em sistema iLPF, sistema Santa Fé e sistema Convencional (Paragominas - PA, 2009)

\begin{tabular}{|c|c|c|c|c|c|c|}
\hline \multirow[b]{2}{*}{ Tratamento } & \multicolumn{2}{|c|}{ Altura } & \multirow{2}{*}{$\begin{array}{c}\text { Umidade } \\
\text { colheita } \\
(\%)\end{array}$} & \multirow{2}{*}{$\begin{array}{l}\text { Produtividade } \\
\quad\left(\mathrm{kg} \cdot \mathrm{ha}^{-1}\right)\end{array}$} & \multirow{2}{*}{$\begin{array}{c}\text { Estande } \\
\text { (planta. } \\
\text { ha }^{-1} \text { ) }\end{array}$} & \multirow{2}{*}{$\begin{array}{c}\text { Produção } \\
\text { palhada } \\
\left(\text { kg.ha }^{-1}\right)\end{array}$} \\
\hline & $\begin{array}{l}\text { planta } \\
(\mathrm{m})\end{array}$ & $\begin{array}{l}\text { espiga } \\
(\mathrm{m})\end{array}$ & & & & \\
\hline iLPF & $2,18 \mathrm{a}^{1}$ & $1,16 \mathrm{a}$ & $23,97 \mathrm{a}$ & $5.764 \mathrm{a}$ & $58.333 \mathrm{a}$ & $4.849 \mathrm{a}$ \\
\hline Santa Fé & $2,18 \mathrm{a}$ & $1,18 \mathrm{a}$ & $25,58 \mathrm{a}$ & $5.788 \mathrm{a}$ & $58.571 \mathrm{a}$ & $5.612 \mathrm{~b}$ \\
\hline Convencional & $2,20 \mathrm{a}$ & $1,21 \mathrm{a}$ & $20,54 \mathrm{~b}$ & $5.848 \mathrm{a}$ & $66.428 \mathrm{~b}$ & $4.946 \mathrm{a}$ \\
\hline CV & 0,52 & 2,13 & $\mathbf{3 , 5 3}$ & 0,75 & $\mathbf{9 , 5 2}$ & 11,58 \\
\hline
\end{tabular}

${ }^{1}$ Médias seguidas de mesma letra na coluna não diferem pelo teste de Scott-Knott a $5 \%$ de probabilidade.

Demétrio et al. (2008) observaram valor semelhante à variável altura de planta com valor médio de $2,35 \mathrm{~m}$, no espaçamento $0,60 \mathrm{~m}$ e estande de 50.000 plantas.ha $^{-1}$, neste estudo. Entretanto, os valores da altura de inserção da primeira espiga foram inferiores $(0,96 \mathrm{~m})$. Obtiveram também aumento dessas variáveis na medida em que se elevou a densidade populacional, não corroborando com os resultados obtidos, pois a diferença no estande de plantas não influenciou as variáveis altura de planta e de inserção de espiga entre os diferentes sistemas avaliados.

Maiores alturas de plantas e de inserção da espiga em razão do aumento da densidade populacional indica uma tendência natural de aumento de altura em plantas em situações de alta densidade (ARGENTA;
SILVA; SANGOI, 2001; ALVAREZ; PINHO; BORGES, 2006). Isto pode ser explicado em razão do efeito combinado intraespecífica por luz, com consequente estímulo da dominância apical das plantas (SANGOI et al., 2002).

Portanto, pode ocorrer redução na altura da planta e espiga, à medida que aumenta-se a população de plantas.ha ${ }^{-1}$, possivelmente, devido à maior competição intraespecífica por água, nutrientes e radiação solar na linha para os maiores estandes (TAKASU et al., 2014).

Plantas de menor altura tem sido um caractere de interesse entre os produtores de milho por permitir cultivos em maiores densidades populacionais e maior eficiência na colheita mecânica como também reduz 
problemas associados ao acamamento e quebramento de plantas antes do ponto de colheita, comumente apresentado por plantas de porte alto (ALMEIDA et al., 2000). Ademais, a menor altura de planta permite maior transposição de luz no dossel (mesmo com alto índice de área foliar) e redução de competição intraespecífica por recursos naturais sob altos estandes de plantas (KAPPES et al., 2011).

A precisão experimental calculada pelo $\mathrm{CV}$ foi considerada normal com valores de CV inferiores a 15\%. Resultados de CV abaixo de $15 \%$ para estas variáveis na cultura foi apresentado por Takusa et al. (2014), onde avaliou-se o milho em diferentes espaçamentos e arranjos populações em Selvíria - MS, obtendo CV de 8,85\% (altura de planta), 6,13\% (altura de espiga) e $8,91 \%$ (produtividade de grãos).

$\mathrm{Na}$ comparação de produtividade, os valores não apresentaram diferença significativa. No entanto, pode-se verificar que os sistemas iLPF e Santa Fé, ambos com população cerca de $14 \%$ menor do que o sistema Convencional, proporcionaram maior produção por indivíduo, calculando a produtividade $\left(\mathrm{kg}_{\mathrm{kga}}{ }^{-1}\right)$ em razão do estande (plantas.ha $^{-1}$ ), ou seja, em torno de 0,1 kg.planta ${ }^{-1}$, sendo essa produção cerca de $13 \%$ superior à obtida no sistema Convencional (Tabela 3).

Em determinada área, o plantio de menores populações de plantas induz a redução da eficiência da radiação solar proporcionando aumento na produção de grãos por indivíduo, porém, reduz a produtividade por área. Por outro lado, maiores populações proporcionam maior produção por área e redução na produtividade por planta. Essa similaridade de produção de grãos e a significante diferença de populações podem ter sido influenciadas, visto que, as populações com números superiores a 60.000 planta.ha ${ }^{-1}$ podem proporcionar declínio na produtividade (SANGOI, 2001; CALONEGO et al., 2011; UBERT et al., 2014).

A produtividade de grãos de milho apresentou incremento linear, com o aumento da população de plantas.ha ${ }^{-1}$ (Tabela 3), sendo que, a média geral de produtividade de grãos $\left(5.800 \mathrm{~kg} \cdot \mathrm{ha}^{-1}\right)$ foi superior à média estadual e nacional da safra 2013/14 (3.232 e $5.401 \mathrm{~kg} \cdot \mathrm{ha}^{-1}$, respectivamente) (CONAB, 2015). Esta maior produtividade, provavelmente, está relacionada, entre outros fatores, aos elevados números de precipitações pluviais (Tabela 2), pois proporcionaram bom desenvolvido dos cultivos, devido à diminuição na competição por água (BERGAMASCHI et al., 2004).

O espaçamento $(0,6 \mathrm{~m})$ entre linhas do plantio de milho, devido ao consórcio com forragem nos sistemas iLPF e Santa Fé, resultou em maior produção de grãos por planta em razão do milho exercer alta competição sobre a forragem, favorecendo o aumento da produção de grãos (KLUTHCOUSKI et al., 2000). Verificou-se que a forragem não afetou o desenvolvimento do milho visto que a Urochloa apresenta crescimento inicial lento (VALLE; PAGLIARINI, 2009) e as plântulas de milho crescimento inicial rápido. A cultura do milho consorciada com forragem perene não influencia na perda de produtividade de grãos (COBUCCI, 2001; BARDUCCI et al., 2009).

A produção de palhada foi superior no sistema Santa Fé $\left(5 \cdot 612,68 \mathrm{~kg} \cdot \mathrm{ha}^{-1}\right)$ devido à grande quantidade de forragem produzida no consórcio com milho. Os demais sistemas não diferiram entre si (Tabela 3 ).

Já o cultivo da forragem em consórcio com milho pode ter auxiliado no combate aos riscos de erosão e compactação do solo pela chuva e proporcionado também maior ciclagem de nutrientes e alternativas viáveis do ponto de vista econômico para o produtor como a forrageira resultante deste sistema de consórcio que pode ser utilizada para pastejo, silagem, silagem seguida de pastejo, fenação e, ainda, cobertura morta (SOUZA et al., 2008).

A produção de Matéria Seca (MS) da Urochloa ruziziensis apresentou média de 10.586 kg.ha ${ }^{-1}$, superior às relatadas por Pariz et al. (2011) (9.240 kg.ha $\left.{ }^{-1}\right)$, onde avaliou-se a produtividade de espécies de braquiárias consorciadas com milho no sistema de 
integração lavoura-pecuária em Selvíria MS.

Nesse contexto, esse sucesso na utilização das Urochloas ocorre em razão de seu sistema radicular apresentar em média 2,0 $\mathrm{m}$ de profundidade, e possuir boa resistência à escassez hídrica quando comparadas com espécies produtoras de grãos, além de apresentar elevada quantidade de massa seca, chegando próximo a $20 \mathrm{t}$ ha $^{-1}$ (KLUTHCOUSKI et al., 2000; COBUCCI, 2001; SANTOS et al., 2007; BARDUCCI et al., 2009; VALLE; PAGLIARINI, 2009; FERREIRA et al., 2010; CRUSCIOL et al., 2012).

O sistema iLPF destacou-se também por agregar valor à área pelo cultivo do mogno africano (Khaya ivorensis), visto que, essa espécie florestal possui bom desenvolvimento nestes sistemas, boa resistência às pragas e alto valor da madeira no mercado (RECH, 2006), podendo ser usado também na produção de sementes. Vale ressaltar, que este sistema além de diversificar a renda do produtor (MARTHA JUNIOR et al., 2011), auxilia no manejo racional do solo e reduz a necessidade de abertura de novas áreas.

\section{CONCLUSÕES}

O desenvolvimento do milho nos sistemas iLPF e Santa Fé foram semelhantes e superiores ao sistema Convencional.

A Urochloa ruziziensis manejada em cultivo consorciado não afetou a produtividade de grãos por área e favoreceu o aumento na produção de grãos por indivíduo do milho em comparação ao sistema Convencional.

\section{AGRADECIMENTOS}

À Empresa Brasileira de Pesquisa Agropecuária, Sr. Thales Barros proprietário da fazenda Vitória, o Projeto iLPF, Projeto PECUS e ao Banco da Amazônia (BASA) e rede de fomento iLPF pelo financiamento da pesquisa.

\section{REFERÊNCIAS}

ALMEIDA, M. L.; MEROTTO JÚNIOR, A.; SANGOI, L.; ENDER, M.; GUIDOLIN, A. F. Incremento na densidade de plantas: uma alternativa para aumentar o rendimento de grãos de milho em regiões de curta estação estival de crescimento. Ciência Rural, Santa Maria, Porto Alegre, RS, v. 30, n. 1, p. 23-29, 2000.

ALVAREZ, C. G. D.; PINHO, R. G.; BORGES, I. D. Avaliação de características agronômicas e de produção de forragens e grãos de milho em diferentes densidades de semeadura e espaçamentos entre linhas. Ciência e Agrotecnologia, v.30, p.402- 408, 2006.

ARGENTA, G. S.; SILVA, P. R. F.; SANGOI, L. Arranjo de plantas em milho: análise do estado da arte. Ciência Rural, v.31, p.1075-1084, 2001.

BALBINO, L. C.; CORDEIRO, L. A. M.; PORFIRIO- DA- SILVA, V.; MORAES, A.; MARTÍNEZ, G. B.; ALVARENGA, R. C.; KICHEL, A. N.; FONTANELI, R. S.; SANTOS, H. P.; FRANCHINI, J. C.; GALERANI, P. R. Evolução tecnológica e arranjos produtivos de sistemas de integração lavoura-pecuária-floresta no Brasil. Pesquisa Agropecuária Brasileira, Brasília, v.46, n.10, p.i-xii, out. 2011.

BARDUCCI, R. S.; COSTA, C.; CRUSCIOL, C. A. C.; BORGHI, É.; PUTAROV, T. C.; SARTI, L. M. N. Produção de Brachiaria brizantha e Panicum maximum com milho e adubação nitrogenada. Archivos de Zootecnia, Córdoba, v. 58, n. 222, p. 211- 222, 2009.

BERGAMASCHI, H.; DALMAGO, G. A.; BERGONCI, J. I.; BIANCHI, C. A. M.; MÜLLER, A. G.; COMIRAN, F.; HECKLER, B. M. M. Distribuição hídrica no período crítico do milho e produção de grãos. Pesquisa Agropecuária Brasileira, Brasília, DF, v. 39, n. 9, p. 831- 839, 2004. 
BLACK, C. A. Methods of Soil Analisys: Part 2 - Chemical and Microbiological Properties. Madison: Amaerican Society of Agronomy, 1965. 1159p.

BRINTHA, I.; SERAN, T. H. Effect of paired row planting of radish (Raphanus sativus L.) intercropped with vegetable amaranthus (Amaranthus tricolor L.) on yield components of radish in Sandy regosol. Journal of Agricultural Sciences, v.4, p.1928, 2009.

CALONEGO, J. C.; POLETO, L. C.; DOMINGUES, F. N.; TIRITAN, C. S. Produtividade e crescimento de milho em diferentes arranjos de plantas. Revista Agrarian, Dourados, v. 4, n. 12, p. 84-90, 2011.

CALONEGO, J. C.; BORGHI, E.; CRUSCIOL, C. A. C. Intervalo hídrico ótimo e compactação do solo com cultivo consorciado de milho e braquiária. Revista Brasileira de Ciência do Solo, Viçosa, v. 35, p. 2183-2190, 2011b.

COBUCCI, T. Manejo integrado de plantas daninhas em sistema plantio direto. In: ZAMBOLIM, L. (Ed.). Manejo integrado fitossanidade: cultivo protegido, pivô central e plantio direto. Viçosa: UFV, 2001. p. 583624.

COMPANHIA NACIONAL ABASTECIMENTO Acompanhamento Safra Brasileira Grãos, v. 2 - Safra 2014/15, n. 7 - Sétimo Levantamento, Brasília, p. 1-100, abr. 2015.

CRUSCIOL, C. A. C.; BORGHI, E. Consórcio de milho com braquiária: produção de forragem e palhada para o plantio direto. Revista Plantio Direto, Passo Fundo, ano 16, n. 100, p. 10-14, jul./ago. 2007.

CRUSCIOL, C. A. C. MATEUS, G. P.; NASCENTE, A. S.; MARTINS, P. O.; BORGHI, E.; PARIZ, C. M. An innovative crop-forage intercrop system: early cycle soybean cultivars and palisadegrass. Agronomy Journal, Madison, v. 104, n. 4, p. 1085-1095, 2012.

DEMÉTRIO, C. S.; FILHO, D. F.; CAZETTA, J. O.; CAZETTA, D. A. Desempenho de híbridos de milho submetidos a diferentes espaçamentos e densidades populacionais. Pesquisa Agropecuária Brasileira, Brasília, v.43, n.12, p.1691-1697, dez. 2008.

EMPRESA BRASILEIRA DE PESQUISA AGROPECUÁRIA (Embrapa). Centro Nacional de Pesquisa de Solos. Sistema brasileiro de classificação de solos. 2. ed. Rio de Janeiro: Embrapa Solos, 2006.

EMPRESA BRASILEIRA DE PESQUISA AGROPECUÁRIA (Embrapa). Manual de métodos de análises do solo. Centro Nacional de pesquisa em solos. Rio de Janeiro: Ministério da Agricultura, 2. ed. 1997. $212 \mathrm{p}$.

EMBRAPA CLIMA TEMPERADO. Reunião Técnica Anual de Milho (58: 2013: Pelotas, RS). LVIII Reunião Técnica Anual de Milho e XLI Reunião Técnica Anual de Sorgo: indicações técnicas para o cultivo de milho e de sorgo no Rio Grande do Sul safras 2013/2014 e 2014/2015 / editores técnicos, Beatriz Marti Emygdio, Ana Paula Schneid Afonso da Rosa e Mauro César Celaro Teixeira. - Brasília, DF: Embrapa, 2013.

FERREIRA, A. C. B.; LAMAS, F. M.; CARVALHO, M. C. S.; SALTON, J. C.; SUASSUNA, N. D. Produção de biomassa por cultivos de cobertura do solo e produtividade do algodoeiro em plantio direto. Pesquisa Agropecuária Brasileira, Brasília, DF, v. 45, n. 6, p. 546-553, 2010.

GUEDES, R. E. RUMJANEK, N. G.; XAVIER, G. R.; GUERRA, J. G. M.; RIBEIRO, R. L. D. Consórcios de caupi e milho em cultivo orgânico para produção de 
grãos e espigas verdes. Horticultura Brasileira, v.28, p.174-177, 2010.

INSTITUTO NACIONAL DE dados/Estações automáticas - gráficos. $2015 . \quad$ Disponível em: <http://www.inmet.gov.br/portal/index.php?r $=$ home/page \&page=rede_estacoes_auto_graf >. Acesso em: 02 fev. 2015.

KAPPES, C.; ANDRADE, J. A. C.; ARF, O.; OLIVEIRA, A. C.; ARF, M. V.; FERREIRA, J. P. Desempenho de híbridos de milho em diferentes arranjos espaciais de plantas. Bragantia, Campinas, v.70, n.2, p.334-343, 2011.

KLUTHCOUSKI, J.; COBUCCI, T.; AIDAR, H.; YOKOYAMA, L. P.; OLIVEIRA, I. P.; COSTA, J. L. S.; SILVA, J. G.; VILELA, L.; BARCELLOS, A. O.; MAGNABOSCO, C. U. Sistema Santa Fé tecnologia Embrapa: integração lavourapecuária pelo consórcio de culturas anuais com forrageiras, em áreas de lavoura, nos sistemas direto e convencional. Santo Antônio de Goiás: Embrapa Arroz e Feijão, 2000.

MARTHA JUNIOR, G. B.; ALVES, E.; CONTINI, E. Dimensão econômica de sistemas de integração lavoura-pecuária. Pesquisa Agropecuária Brasileira, Brasília, v. 46, n. 10, p. 1117-1126, 2011.

NASCIMENTO, R. S.; CARVALHO, N. L. Integração lavoura-pecuária. Monografias ambientais - REMOA/UFSM, Santa Maria, v.4, n.4, p. 828-847, 2011.

PARENTONI, S. N.; GAMA, E. E. G.; SANTOS, M. X.; PACHECO, C. A. P.; GUIMARÃES, P. E. O.; MEIRELLES, W. F.; RIBEIRO, P. H. E.; CORREA, L. A.; CASELA, C. R.; FERREIRA, A. S.; ALVES, V. M. C.; FERNANDES, F. T.; OLIVEIRA, A. C.; PEREIRA, F. T. F. Milho Híbrido Simples BRS 1030. Comunicado técnico
108, ISSN 0101-5605, Dezembro, Sete Lagoas, MG. 2004.

PARIZ, C. M.; ANDREOTTI, M.; AZENHA, M. V.; BERGAMASCHINE, A. F.; MELLO, L. M. M.; LIMA, R. C.; Produtividade de grãos de milho e massa seca de braquiárias em consórcio no sistema de integração lavoura-pecuária. Ciência Rural, Santa Maria, v.41, n.5, p.875-882, 2011.

RODRIGUES, C. C.; KITAMURA, P. C. Jaguariúna: Embrapa Meio Ambiente, 2003. 95p. (Embrapa Meio Ambiente. Documentos, 34) Rodrigues, G. S. [et al.]. Sistema de Avaliação de Impacto Social da Inovação Tecnológica Agropecuária (AmbietcSocial)/.. - Jaguariúna: Embrapa Meio Ambiente, 2005. 31 p. - (Boletim de Pesquisa e Desenvolvimento/Embrapa Meio Ambiente, ISSN 1516-4675; 35).

SANGOI, L. Understanding plant density effects on maize growth and development: an important issue to maximize grain yield. Ciência Rural, Santa Maria, v. 31, n. 1, p. 159-168, 2001.

SANGOI, L.; GRACIETTI, M. A.; RAMPAZZO, C.; BIANCHET, P. Response of Brazilian maize hybrids from different eras to changes in plant density. Field Crops Research, v.79, p.39-51, 2002.

SANTOS, R. D. Características agronômicas de variedades de milho para produção de silagem. Acta Scientiarum. Animal Sciences, v. 32, n. 4, p. 367-373, 2010.

SANTOS, R. S. M.; OLIVEIRA, I. P.; MORAIS, R. F.; URQUIAGA, S. C.; BODDEY, R. M.; ALVES, B. J. R. Componentes da parte aérea e raízes de pastagens de Brachiaria spp. em diferentes idades após a reforma, como indicadores de produtividade em ambiente de Cerrado. Pesquisa Agropecuária Tropical, Goiânia, v. 37, n. 2, p. 119-124, 2007. 
SILVA, A. G.; TEIXEIRA, I. R.; MARTINS, P. D. S.; SIMON, G. A.; FRANCISCHINI, R. Desempenho agronômico e econômico de híbridos de milho na safrinha. Revista Agroambiente, v. 8, n. 2, p. 261-271, maioagosto, 2014.

SOUZA, E. D.; COSTA, S. E. V. G. A.; LIMA, C. V. S.; ANGHINONI, I.; MEURER, E. J.; CARVALHO, P. C. F. Carbono orgânico e fosforo microbiano em sistema de integração lavoura-pecuária submetido a diferentes intensidades de pastejo em plantio direto. Revista Brasileira de Ciência do Solo, Campinas, v. 32, p. 1273-1282, 2008.

SOUZA, L. S. B.; MOURA, M. S. B.; SEDIYAMA, G. C.; SILVA, T. G. F. Eficiência do uso da água das culturas do milho e do feijão-caupi sob sistemas de plantio exclusivo e consorciado no semiárido brasileiro. Bragantia, v.70, p.715- 721, 2011.

RECH, C. Estados Unidos lidera importações brasileiras. Revista da Madeira, 96. 2006.

UBERT, I. P.; ALMEIDA, C. A. S.; CHIODELLI, E.; BRESOLIN, F.; CASTANHO, M.; SOLIGO, S.; CAMILLO, M. F. Efeito de diferentes densidades na produtividade de grãos de milho (zea mays 1.) em espaçamento reduzido. RAMVI, Getúlio Vargas, v. 01, n. 01, jan./ jun. 2014.

TAKASU, A. T.; RODRIGUES, R. A. F.; GOES, R. J.; ARF. O.; HAGA, K. I. DESEMPENHO agronômico do milho sob diferentes arranjos populacionais e espaçamento entrelinhas. Revista Agrarian, Dourados, v.7, n.23, p. 34-41, 2014.

VALLE, C. B.; PAGLIARINI, M. S. Biology, citogenetics, and breeding of Brachiaria. In: SINGH, R. J. (Ed.). Genetic resources, chromosome engineering, and crop managements. Boca Raton: CRC, p. 103-152. 2009. 